\title{
GLAUCOMA DRAINAGE DEVICE: A REVIEW
}

P. Mishra ${ }^{1}$, Parth Rana ${ }^{2}$, S. Manavalan ${ }^{3}$, Neha $H^{4}$, Abbin G. M5, V. S. Naggalakshmi ${ }^{6}$, Latha Priyangaa ${ }^{7}$, R. Vinnarasi ${ }^{8}$

\section{HOW TO CITE THIS ARTICLE:}

P. Mishra, Parth Rana, S. Manavalan, Neha H, Abbin G. M, V. S. Naggalakshmi, Latha Priyangaa, R. Vinnarasi. "Glaucoma Drainage Device: A Review". Journal of Evolution of Medical and Dental Sciences 2014; Vol. 3, Issue 62, November 17; Page: 13744-13758, DOI: 10.14260/jemds/2014/3837

ABSTRACT: Most GDDs have been developed in a virtual publication vacuum, with little available data to substantiate manufacturers' claims for flow performance or biocompatibility. Clinical data are largely restricted to uncontrolled retrospective case series with variable follow up and differing definitions of surgical success. Evaluation is further complicated by the heterogeneity of inclusion criteria. This review article highlights various GDDs, which will be a great help to ophthalmologists as well as post graduate students in Ophthalmology.

KEYWORDS: Glaucoma Drainage Devices, Glaucoma Filtering Surgery, Glaucoma stent, Ex-PRESS Shunt, I Stent, EYEPASS stent, Cypass micro stent.

INTRODUCTION: Glaucoma filtration surgery (GFS) has been shown to be more effective at preventing disease progression than other primary treatment modalities in open angle glaucoma. Trabeculectomy, the procedure of choice in conventional GFS, has remained essentially unchanged for over a quarter of a century. With use of antimetabolite agents such as 5- Fluorouracil and Mitomycin C has improved the prognosis for cases with high risk of filtration failure; but flow control remains inexact despite the introduction of a variety of suture adjustment techniques. ${ }^{1}$

Glaucoma drainage devices (GDDs) have the potential to regulate flow consistently, eliminating hypotony after GFS. Design, material, and manufacturing deficiencies have left this potential unfulfilled in existing GDDs, all of which exhibit problems with poor flow control and suboptimal tissue compatibility. The role of GDDs in contemporary GFS remains poorly defined, but possibilities offered by new biomaterials and the goal of accurate flow control have stimulated considerable interest in recent GDD development. This review traces the progress of GDD design through to the present and beyond.

EARLY GLAUCOMA DRAINAGE DEVICES: Initially, attention has focused on devices shunting aqueous fluid to the sub-conjunctival space. ${ }^{2}$ First translimbal GDD, reported by Zorab in 1912, was silk thread used as a seton to aid drainage of anterior chamber fluid to the subconjunctival space. This was followed by similar use of gold, tantalum, and platinum thread/wire. Results were universally poor as these and other early translimbal setons (Table 1) did not address lack of flow control and hypotony associated with full thickness (unguarded) GFS, and added a foreign body chronic inflammatory stimulus.

Simple translimbal tube devices were similarly unsuccessful, with high rates of early filtration failure. ${ }^{2}$ Translimbal drainage implants, or anterior GDDs, were implanted with the intention of preventing filtration failure by maintaining patency of a drainage fistula or sclerostomy. Anterior GDDs failed to improve filtration failure rates in comparison with conventional GFS, but it took almost half a century for investigators to begin to rationalise this lack of success. ${ }^{3}$ In 1969, Molteno 


\section{REVIEW ARTICLE}

hypothesized that filtration failure was primarily attributable to subconjunctival fibrosis, with fistula closure occurring as a secondary event.

This was later confirmed in histological studies of animal models of GFS. Realizing that simple anterior GDDs would have little impact on this process, Molteno launched the concept of tube and plate GDDs (Fig. 4) in which aqueous fluid is shunted to a plate device designed to maintain patency of a subconjunctival filtration reservoir in the face of continuing subconjunctival fibrosis. Although confined to use in complex cases by the advent of trabeculectomy and relatively successful conventional guarded GFS, these were the first GDDs to gain widespread acceptance and the Molteno tube remains the benchmark against which other tube devices are compared. ${ }^{3}$

\section{TYPES OF IMPLANTS:}

1. Non-valved/Non-restrictive implants: These GDDs consist of a silicone tube attached to an endplate that acts as a surface for the bleb formation. Like Molteno implant, Baerveldt implant, Schocket implant, Ex-Press R50.

2. Valved/Restrictive implants: $A G V$ is a silicone tube connected to a silicone sheet valve held in a polypropylene body. The valve is designed to open when intra-ocular pressure (IOP) is 8 mmHg. Krupin slit valve consists of a silicone tube with a slit valve attached to a silicone oval endplate with a surface area of $180 \mathrm{~mm}^{2}$. The opening pressure of the slit valve is designed to be 11-14 mmHg and the closing pressure is designed to be $2 \mathrm{~mm} \mathrm{Hg}$. Others: Joseph, Optimed and White GDD.

3. GDD with variable resistance: Molteno dual ridge device limits the initial drainage area by dividing the top portion of the plate into two separate spaces with a thin V-shaped ridge. Baerveldt bioseal is a flap that overhangs the silicone tube as it opens on the endplate. SOLX Goldshunt is an investigational device consisting of a flat, 24 carat gold implant $(5.2 \mathrm{~mm}$ long and $3.2 \mathrm{~mm}$ wide) with numerous microtubular channels that bridge the $\mathrm{AC}$ and the suprachoroidal space.

\begin{tabular}{|l|l|c|c|c|c|l|}
\hline Year & Investigator & Type & Material & Method & $\begin{array}{c}\text { Flow } \\
\text { control }\end{array}$ & Drainage site \\
\hline 1907 & Rollet & seton & Horse hair & Paracentesis & None & External cornea \\
\hline 1912 & Zorab & seton & Silk thread & Translimbal & None & $\begin{array}{l}\text { Anterior } \\
\text { subconjunctival }\end{array}$ \\
\hline 1925 & Stefansson & $\begin{array}{c}\text { seton/ } \\
\text { tube }\end{array}$ & Gold & Translimbal & None & $\begin{array}{l}\text { Anterior } \\
\text { subconjunctival }\end{array}$ \\
\hline 1934 & Row & seton & Platinum & Cyclodialysis & None & Suprachoroidal \\
\hline 1940 & Troncoso & seton & Magnesium & Cyclodialysis & None & Suprachoroidal \\
\hline 1942 & Gibson & $\begin{array}{c}\text { tube } \\
\text { Lacrimal }\end{array}$ & Transcleral & None & $\begin{array}{l}\text { Anterior } \\
\text { subconjunctival }\end{array}$ \\
\hline 1949 & Bick & $\begin{array}{c}\text { seton/ } \\
\text { tube }\end{array}$ & Tantanium & Cyclodialysis & None & Suprachoroidal \\
\hline
\end{tabular}


REVIEW ARTICLE

\begin{tabular}{|c|c|c|c|c|c|c|}
\hline 1951 & Muldoon & seton & Platinum & Translimbal & None & $\begin{array}{l}\text { Anterior } \\
\text { subconjunctival }\end{array}$ \\
\hline 1952 & Losche & tube & Supramid & Cyclodialysis & None & Suprachoroidal \\
\hline 1955 & Bietti & tube & Polyethylene & Cyclodialysis & None & Suprachoroidal \\
\hline 1958 & La Rocca & tube & Polyvinyl & Translimbal & None & $\begin{array}{l}\text { Anterior } \\
\text { subconjunctival }\end{array}$ \\
\hline 1960 & Ellis & tube & Silicone & Translimbal & None & $\begin{array}{l}\text { Anterior } \\
\text { subconjunctival }\end{array}$ \\
\hline 1967 & Mascati & tube & Plastic & Translimbal & None & Lacrimal sac \\
\hline 1969 & Molteno l & $\begin{array}{c}\text { tube and } \\
\text { plate }\end{array}$ & Acrylic & Translimbal & None & $\begin{array}{l}\text { Anterior } \\
\text { subconjunctiva }\end{array}$ \\
\hline 1974 & Lee and Wong & tube & Collagen & Translimbal & None & Vortex vein \\
\hline 1976 & Krupin & tube & $\begin{array}{c}\text { Silicone and } \\
\text { supramid }\end{array}$ & Translimbal & Slit valve & $\begin{array}{l}\text { Anterior } \\
\text { subconjunctival }\end{array}$ \\
\hline 1979 & Honrubia & tube & Silicone & Translimbal & None & $\begin{array}{l}\text { Anterior } \\
\text { subconjunctival }\end{array}$ \\
\hline 1982 & Schocket & $\begin{array}{c}\text { tube and } \\
\text { band }\end{array}$ & Silicone & Translimbal & None & $\begin{array}{l}\text { Posterior } \\
\text { subconjunctival }\end{array}$ \\
\hline 1985 & White & $\begin{array}{c}\text { tube and } \\
\text { plate }\end{array}$ & Silicone & Translimbal & $\begin{array}{l}\text { Valve and } \\
\text { pump }\end{array}$ & $\begin{array}{l}\text { Posterior } \\
\text { subconjunctival }\end{array}$ \\
\hline 1986 & Joseph & $\begin{array}{c}\text { tube and } \\
\text { band }\end{array}$ & Silicone & Translimbal & Slit valve & $\begin{array}{l}\text { Posterior } \\
\text { subconjunctival }\end{array}$ \\
\hline 1990 & Krupin & $\begin{array}{c}\text { tube and } \\
\text { plate }\end{array}$ & Silicone & Translimbal & Slit valve & $\begin{array}{l}\text { Posterior } \\
\text { subconjunctival }\end{array}$ \\
\hline 1990 & Baerveldt & $\begin{array}{c}\text { tube and } \\
\text { plate }\end{array}$ & Silicone & Translimbal & None & $\begin{array}{l}\text { Posterior } \\
\text { subconjunctival }\end{array}$ \\
\hline 1993 & Ahmed & $\begin{array}{l}\text { tube and } \\
\text { plate }\end{array}$ & $\begin{array}{c}\text { Silicone and } \\
\text { polypropyle } \\
\text { ne }\end{array}$ & Translimbal & $\begin{array}{l}\text { Venturi } \\
\text { valve }\end{array}$ & $\begin{array}{l}\text { Posterior } \\
\text { subconjunctival }\end{array}$ \\
\hline 1995 & OptiMed & $\begin{array}{c}\text { tube and } \\
\text { plate }\end{array}$ & $\begin{array}{c}\text { Silicone and } \\
\text { PMMA }\end{array}$ & Translimbal & Microtubules & $\begin{array}{l}\text { Posterior } \\
\text { subconjunctival }\end{array}$ \\
\hline 1995 & Smith & seton & Hydrogel & Translimbal & None & Intrascleral \\
\hline 1996 & Pandya & $\begin{array}{c}\text { tube and } \\
\text { plate }\end{array}$ & $\begin{array}{c}\text { Silicone and } \\
\text { hydroxylapa } \\
\text { tite }\end{array}$ & Translimbal & None & $\begin{array}{l}\text { Posterior } \\
\text { subconjunctival }\end{array}$ \\
\hline 1997 & $\begin{array}{l}\text { Glovinsky and } \\
\text { Belkin }\end{array}$ & tube & $\begin{array}{c}\text { Stainless } \\
\text { steel }\end{array}$ & Translimbal & None & $\begin{array}{l}\text { Anterior } \\
\text { subconjunctival }\end{array}$ \\
\hline 1997 & Helies & $\begin{array}{c}\text { artificial } \\
\text { meshwo } \\
\text { rk }\end{array}$ & PTFE & Transcleral & None & $\begin{array}{l}\text { Anterior } \\
\text { subconjunctival }\end{array}$ \\
\hline 2002 & $\begin{array}{l}\text { ExPRESS } \\
\text { miniature }\end{array}$ & $\begin{array}{c}\text { tube and } \\
\text { plate }\end{array}$ & $\begin{array}{c}\text { Stainless } \\
\text { steel }\end{array}$ & Transcleral & None & $\begin{array}{l}\text { Anterior } \\
\text { subconjunctival }\end{array}$ \\
\hline
\end{tabular}




\section{REVIEW ARTICLE}

\begin{tabular}{|c|c|c|c|c|c|c|}
\hline & $\begin{array}{l}\text { glaucoma } \\
\text { shunt (Fig 5) }\end{array}$ & & & & & \\
\hline 2003 & $\begin{array}{l}\text { Reay Brown } \\
\text { and Mary } \\
\text { Lynch: } \\
\text { EYEPASS } \\
\text { glaucoma } \\
\text { shunt (Fig 6) }\end{array}$ & tube & silicone & Transcleral & None & $\begin{array}{l}\text { Anterior } \\
\text { subconjunctival }\end{array}$ \\
\hline 2004 & $\begin{array}{l}\text { Richard Hill } \\
\text { and Mory } \\
\text { Ghareb: } \\
\text { i-Stent (Fig 7) }\end{array}$ & tube & $\begin{array}{l}\text { surgical } \\
\text { grade } \\
\text { titanium }\end{array}$ & Translimbal & None & $\begin{array}{l}\text { Anterior } \\
\text { subconjunctival }\end{array}$ \\
\hline 2005 & $\begin{array}{l}\text { Deep light Gold } \\
\text { shunt (Fig 8) }\end{array}$ & Plate & $\begin{array}{l}\text { medical- } \\
\text { grade } \\
(99.95 \%) \\
\text { gold }\end{array}$ & Translimbal & None & $\begin{array}{l}\text { Anterior } \\
\text { subconjunctival }\end{array}$ \\
\hline 2009 & $\begin{array}{l}\text { Bruce Shields: } \\
\text { Aquashunt }\end{array}$ & tube & silicone & Translimbal & None & $\begin{array}{l}\text { Anterior } \\
\text { subconjunctival }\end{array}$ \\
\hline 2009 & $\begin{array}{l}\text { Transcend } \\
\text { CyPass } \\
\text { glaucoma } \\
\text { implant (Fig 9) }\end{array}$ & Tube & Polyimide & $\begin{array}{c}\text { supraciliary } \\
\text { space }\end{array}$ & None & $\begin{array}{l}\text { Supra } \\
\text { Choroidal }\end{array}$ \\
\hline
\end{tabular}

INDICATIONS: Glaucoma drainage device implantation is usually reserved for cases with refractory glaucoma, or those unlikely to respond successfully to a conventional filtration surgery. The Indications for GDD implantation include the following:

- Neovascular glaucoma.

- Penetrating Keratoplasty with glaucoma.

- Retinal Detachment surgery with glaucoma.

- Iridocorneal endothelial syndrome.

- Traumatic glaucoma.

- Uveitic glaucoma.

- Open angle glaucoma with failed trabeculectomy.

- Epithelial down growth.

- Refractory infantile glaucoma.

- Contact lens wearers who need glaucoma filtration surgery.

- Sturge-Weber's syndrome.

- Pseudo-exfoliation Glaucoma.

- Pigmentary Glaucoma.

- Aphakic Glaucoma. 


\section{CONTRAINDICATIONS:}

- Eyes with severe scleral or sclera-limbal thinning.

- Extensive fibrosis of conjunctiva.

- Ciliary block glaucoma.

\section{RELATIVE CONTRAINDICATIONS:}

- Vitreous in AC.

- Intra-ocular silicone oil-Implant if required is placed in inferio-temporal quadrant.

\section{GDDS IN RECENT USE:}

EX-PRESS GLAUCOMA FILTRATION DEVICE4: The Ex PRESS shunt is on the forefront of evolution towards smaller incision glaucoma filtration surgery. Since there is an added cost to using the ExPRESS rather than trabeculectomy, its place in the surgical management of glaucoma has not been universal.

DEVICE: Ex-PRESS stands for "excessive pressure regulating shunt system". The Ex-PRESS implant is a miniature unvalved glaucoma implant. It was originally developed by Optonol, Ltd. (Neve Ilan, Israel), as an alternative procedure to trabeculectomy and to the other types of glaucoma filtering surgery for patients with open angle glaucoma. Now, it is available as EX-PRESS Glaucoma Filtration Device. The device is approximately $3 \mathrm{~mm}$ long, stainless steel tube (outer diameter $400 \mu \mathrm{m}(27$ gauge)) with a bevelled, sharpened, rounded tip, a disc-like flange $(<1 \mathrm{~mm}, 2)$ at the device proximal end, and a spur-like projection that prevents its extrusion(Fig 5).

The external flange and inner spur are angled to conform to the anatomy of the sclera, and the distance between them corresponds to the scleral thickness at the site of implantation. The EX-PRESS Glaucoma Filtration Device is preloaded on a specially designed disposable introducer, the EX-PRESS Delivery System (EDS). The EDS is an inserter designed to maintain the correct orientation of the EXPRESS $®$ Glaucoma Filtration Device throughout implantation procedure. The commercially available versions are: R-50, P-50 and P-200 (Fig. 5)

SURGICAL PROCEDURE: Originally, the device was designed to be inserted at the limbus directly under the conjunctiva with formation of a subconjunctival bleb which served as a flow modulator. Poor conjunctival covering of the device, conjunctival erosions over the external flange and conjunctival scarring with subsequent decreased aqueous humour filtration, were some of the complications that were encountered because of direct subconjunctival implantation.

Conjunctivoplasty or tube removal had to be performed to avoid secondary infection. To overcome these complications, implanting the device under a limbus based $50 \%$ deep scleral flap extending into clear cornea. This operation is similar to standard trabeculectomy without the need of an iridectomy or scleral removal. This implant may also be used in deep sclerectomy to simplify the difficult dissection of Schlemm's canal and Trabeculo-Descemet's membrane.

PLACEMENT OF DEVICE UNDER A SCLERAL FLAP: To place the Ex-PRESS filtration device, a conjunctival peritomy, limbal or fornix-based, is first created as in conventional trabeculectomy. Gentle cautery is applied to the sclera prior to creation of a scleral flap. The dimensions of the scleral 
flap may need to be slightly larger than the trabeculectomy flap and it should be initiated more posteriorly in order to ensure full coverage of the shunt plate.

Scleral spur is identified by a white, glistening band of fibers that crosses the bed of this section. The blue zone is a transition zone to the clear cornea. The surgeon should make sure that they implant the EX-PRESS device in the anterior chamber, just at the level of the sclera spur, but not too far posteriorly.

It is important for the device to enter the eye exactly at the anterior aspect of the scleral spur and for it to remain at the iris plane so that it does not point downward towards the iris. Once the scleral spur has been visualized, the anterior chamber should be filled with viscoelastic or air in the area of anticipated shunt entry. Rather than an ostium created by a punch, trephine, or scissors, a 25or 27-gauge needle or a $400 \mu \mathrm{m}$ wide blade is used to enter the anterior chamber at the level of the scleral spur, parallel to the iris, and the Ex-PRESS device is injected into this needle tract.

The Ex-PRESS device relies on non-physiologic sub-conjunctival flow as its mechanism of IOP lowering. As a result, all of the issues that limit trabeculectomy and the complication profile associated with blebs accompany the Ex-PRESS shunt too, but to a much lesser extent. Recently, external blockade of the tube has been reported as a possible device-related complication of ExPRESS implants, which can be visualized on a systematic gonioscopic examination. It should be considered whenever IOP increases and a flat bleb is observed.

Neodymium: Yttrium Argon Garnet (Nd. YAG) laser at the tip of the device is a viable therapeutic option to treat the external occlusion of Ex-PRESS devices, regardless the nature of the obstruction. Obstruction may also occur inside the lumen of the device where it may not be visualized by gonioscopy, at the point where the diameter constricts to $50 \mathrm{~mm}$. Since this constriction point is close to the opening into the anterior chamber, Nd.YAG laser works in this scenario as well. Corneal dislocation of the Ex-PRESS implant may occur and when associated with ocular hypertension, needs surgical treatment.

ISTENT5: DEVICE: The iStent trabecular micro-bypass stent (Glaukos Corp, Laguna Hills, California) is the first ab-interno micro bypass stent. It is a heparin-coated with Duraflo (Edwards Lifesciences, Irvine, CA), nonferromagnetic, surgical grade titanium (Ti6Al4V ELI) stent less than one mm in length and approximately $0.3 \mathrm{~mm}$ in height, with a snorkel length of $0.25 \mathrm{~mm}$ and a nominal snorkel bore diameter of $120 \mu \mathrm{m}$. It is about 1/5000 of the size of the Baerveldt implant. (Samuelson et al., 2011) The iStent is inserted through a small temporal clear corneal incision, bypassing the trabecular meshwork, and placed in Schlemm's canal at the lower nasal quadrant. The dimensions of the stent are customized for a natural fit and retention within the $270 \mu$ canal space, with three retention arches to ensure secure placement. (Fig. 7)

SURGICAL TECHNIQUE: The iStent is preloaded in a single-use, light release force, sterile applicator with a secure, rotatable grip to facilitate manipulation and placement into Schlemm's canal. Separate orientations of the stent are available for the right and left eye. iStent implantation can be performed under topical anaesthesia. Prior to implanting the iStent, the angle anatomy and targeted stent site must be in clear view. The Swan-Jacob gonioprism is used to inspect the angle to ensure a good view at the nasal implant location. 
The iStent is implanted through the same small, temporal, clear corneal incision used for phacoemulsification or a $1.5 \mathrm{~mm}$ incision when the stent is implanted as a stand-alone procedure. iStent in inserted in trabecular meshwork with "Penetrate, lift and slide" insertion technique. For best possible angle visualization; iStent insertion should be performed from the temporal side with the microscope magnified $12 \mathrm{X}$ and tilted towards the surgeon. The patient's head is tilted away from the surgeon. Implantation is performed in the nasal position (3 to 4 o'clock for the right eye; 8 to 9 o'clock for the left eye) with the tip of the implant directed inferiorly. The tip of the stent should approach the trabecular meshwork at $15^{\circ}$ angle to facilitate penetration of the tissue.

Excessive resistance indicates that the approach is too perpendicular to the trabeculum. Once the stent is covered with meshwork it is released by pressing the applicator button. Only the proximal end of the stent remains visible in the anterior chamber. The iStent is seated into position by gently tapping the side of the snorkel with the applicator tip. A small reflux of blood from the Schlemm's canal reflects correct positioning of the stent.

The stent is small $(1 \mathrm{~mm})$ and hence it may sometimes be difficult to verify exact placement of the implant via gonioscopy, particularly in cases of corneal oedema, peripheral anterior synechiae, or an uncooperative or anxious patient. In such cases there is a possibility of accidentally misplacing the iStent. A theoretical problem with bypass of the meshwork is blood reflux from Schlemm's canal into the anterior chamber via the tube, creating a microhyphema.

DEEPLIGHT GOLD MICRO SHUNT6: DEVICE: The GMS (SOLX Ltd, Boston, Massachusetts) is a nonvalved flat-plate drainage device made from $24-\mathrm{K}$ medical-grade (99.95\%) gold. The device is composed of two leaflets fused together vertically concealing nine channels within the body that connect the anterior openings to the posterior ones. Two different models of the device exist, the GMS (XGS-5) and the GMS Plus (XGS-10), both measuring $5.2 \mathrm{~mm}$ long, $2.4 \mathrm{~mm}$ wide anteriorly and 3.2 $\mathrm{mm}$ wide posteriorly, but differing in weight and channel size.

The XGS-5 model weighs $6.2 \mathrm{mg}$ and is $60 \mathrm{~mm}$ in thickness with the channels measuring $25 \mathrm{~mm}$ in width and $44 \mathrm{~mm}$ in height while the XGS-10 model weighs $9.2 \mathrm{mg}$ and the channels measure $25 \mathrm{~mm}$ in width by $68 \mathrm{~mm}$ in height. Aqueous humor from the anterior chamber exiting through the uveoscleral pathway to the suprachoroidal space is enhanced by this device by allowing fluid to travel both through the channels in the shunt and also around the body of the shunt.(Fig 8)

SURGICAL PROCEDURE: The scleral dissection is carried out to near full thickness depth, where the choroid is visible through a thin layer of sclera. A scleral pocket at $95 \%$ depth is then created by tunneling anteriorly towards the scleral spur. At this point, a vertical incision is made into the choroidal space and a small amount of suprachoroidal anaesthesia and viscoelastic are administered with a blunt cannula. Through a sideport incision, viscoelastic is filled in the anterior chamber at the anticipated site of entry of the gold shunt.

Positioning of the shunt is achieved posteriorly in the suprachoroidal space using a sharp 27gauge needle against the shunt to gently encourage it into the suprachoroidal pocket expanded previously by viscoelastic while grasping the wound with a toothed forceps. A "Push then pull" approach works well while inserting the shunt through scleral incision in the anterior chamber. Alternatively, an instrument such as a Sinskey hook can be utilized on the lateral positioning holes. 
All of the shunt openings on the posterior aspect should be concealed under the posterior scleral lip of the wound.

The anterior aspect of the wound can also be manipulated through the anterior chamber to aid in positioning of the shunt. Intraoperative gonioscopy can help to confirm the proper and intended positioning of the gold shunt in the anterior chamber. The overlying scleral wound is tightly sutured with 4-5 interrupted 10-0 nylon sutures to ensure watertight closure, as subconjunctival reservoir is not the intended mode of filtration in this surgical procedure. Finally, a 10-0 vicryl horizontal mattress suture is placed to reappose conjunctiva. The crescent-shaped anterior aspect of the shunt consists of a positioning hole, which can be used to adjust shunt positioning with an instrument such as a Sinskey hook.

The posterior aspect of the shunt likewise possesses two lateral wings for shunt manipulation. Flow is directed through and around the shunt via the natural pressure gradient from the anterior chamber to the suprachoroidal space. Mild hyphema, hypotony, choroidal effusion, hemorrhage or detachment and shunt migration have been noted in few cases, in decreasing order of their occurrence.

EYEPASS BI-DIRECTIONAL GLAUCOMA IMPLANT6: DEVICE: The Eyepass Bi-Directional glaucoma implant (GMP Vision Solutions, Inc.) consists of a dual $6.0 \mathrm{~mm}$ long silicone tube bonded at 1 end for less than $1.0 \mathrm{~mm}$, creating a Y-shape. The inner diameter of the silicone tube is $125 \mu \mathrm{m}$ and the outer diameter is $250 \mu \mathrm{m}$, making the tube narrow enough to fit the lumen of the Schlemm canal. The implant is sterilized by gamma radiation and is a single-use device that should be stored at a temperature between $15^{\circ} \mathrm{C}$ and $30^{\circ} \mathrm{C}$ (Fig 6).

SURGICAL PROCEDURE: It can be used as a standalone procedure or in combination with cataract surgery. After a fornix-based superomedial conjunctival dissection and a mild wet field cautery, a two-third thickness triangular scleral flap with a $4 \mathrm{~mm}$ basis is dissected. Before the Schlemm canal is unroofed, clear corneal cataract surgery is performed. This is followed by the Schlemm canal unroofing by dissecting a second scleral flap or by opening the canal with small Vannas scissors. Before the Eyepass device is implanted in both lumina of the Schlemm canal, the openings on both sides of the canal are dilated by gentle injection of an OVD such as sodium hyaluronate $1.0 \%$ [Healon] through a viscocanalostomy cannula.

Thereafter, the arms of the "Y" are inserted into the lumina of the Schlemm canal without exerting pressure in the direction of the anterior chamber. After both ends are buried in the Schlemm canal, the bonded end is inserted into the anterior chamber via a paracentesis almost $1.0 \mathrm{~mm}$ from the trabecular meshwork, toward the center of the anterior chamber and under the scleral flap. The implant does not need to be secured by sutures. The scleral flap is sutured to a watertight fit using interrupted 10-0 nylon sutures. The conjunctiva is closed with 8-0 polyglactin (Vicryl) sutures at the limbus.

CYPASS MICRO STENT6: DEVICE: Cypass (Transcend) is made from a biocompatible material (polyimide) and features a unique delivery system. The CyPass is a micro-implantable device, $6 \mathrm{~mm}$ in length, with a small lumen of $300 \mu$. It allows for an ab-interno surgical approach, which spares the conjunctiva, does not penetrate the sclera and leaves the trabecular meshwork intact. (fig 9) 
SURGICAL PROCEDURE: It is implanted in the suprachoroidal space through a clear corneal incision, which coincides with the phacoemulsification incision in combined procedures. A special inserter is used to make the distal end of the device penetrate into the suprachoroidal space, while the proximal collar remains in the anterior chamber. Three rings on the collar keep the device in place, preventing movement.

COMPLICATIONS: The origin of most complications can be traced to just two fundamental mechanisms poor flow control and suboptimal material biocompatibility. ${ }^{7}$

1) POOR FLOW CONTROL: Poor flow control after GFS leads directly to hypotony (IOP $<5 \mathrm{~mm}$ $\mathrm{Hg}$ ), anterior chamber flattening, and choroidal detachment. Sight threatening complications, including hypotony maculopathy and delayed suprachoroidal haemorrhage may result. ${ }^{8}$

2) NO RESISTANCE MECHANISM: Early Molteno and Baerveldt implants were simple tube and plate devices with no internal resistance mechanism. After GFS, resistance to flow distal to the sclerostomy or GDD generally remains low until limited subconjunctival wound healing has occurred and the initially diffuse aqueous escape becomes confined within a maturing filtration bleb. ${ }^{9}$

3) No Set Resistance: Later versions of the Molteno and Baerveldt GDD incorporate resistance mechanisms which depend on tissue apposition to limit flow.

The Molteno dual ridge device seeks to limit the initial drainage area by dividing the top part of the plate into two separate spaces. Aqueous escapes directly into the channel between two concentric ridges on the plate element, but must overcome resistance associated with conjunctival tissue apposition to flow further. With later partial encapsulation of the plate element, the overlying tissue balloons clear of the inner pressure ridge, and aqueous flow into the space overlying the plate is unrestricted. ${ }^{10}$

Apposition of the "Bioseal" element of the modified Baerveldt implant to the sclera with absorbable sutures also aims to provide early flow resistance, limiting initial aqueous escape from beneath the device.

The essential problem with both approaches is that, as with trabeculectomy, the force of tissue apposition is poorly controlled. Early flow resistance varies and initial IOP levels remain unpredictable.

4) SET RESISTANCE: Devices which aim to set the initial IOP level by incorporating a nonadjustable resistance mechanism include the Krupin, Ahmed and OptiMed GDDs. Independent examination of the flow characteristics for each of these devices suggests a wide divergence between observed function and manufacturers' claims for flow resistance. Valved devices (Ahmed and Krupin) appear not to close after initial opening in perfusion tests at physiological flow rates. Resistance values also vary considerably between devices from the same manufacturer, indicating deficiencies in quality control.

5) SUBOPTIMAL TISSUE COMPATIBILITY: ${ }^{11,12}$ Tissue compatibility refers to the ability of a synthetic material to interface with living tissues without provoking a detrimental reaction. Within the context of GDD implantation, suboptimal tissue compatibility is manifest in an array of complications including early fibrinous occlusion, corneal endothelial failure, tube migration, extrusion, and fibrous encapsulation leading to filtration failure. Progressive fibrous 


\section{REVIEW ARTICLE}

encapsulation limits the filtration life of all contemporary GDDs. As with poor flow control, suboptimal tissue compatibility and the resultant low grade inflammatory drive to progressive subconjunctival fibrosis have not yet been adequately addressed.

6) PLATE SURFACE AREA: One strategy for delaying filtration failure has been to increase plate surface area. In 1981, Molteno published a series of 20 patients who received one plate (135 $\mathrm{mm})$, two plate $(270 \mathrm{~mm} 2)$, or four plate $(540 \mathrm{~mm} 2)$ Molteno implants. Mean postoperative IOPs were significantly lower for two and four plates compared with single plate implantation, but did not differ significantly between two and four plates. Overall, a larger filtration area would appear to improve filtration function, at least in the medium term, but eventual subconjunctival fibrosis over a wider area may adversely influence the prognosis for repeat GFS. 13

THE FUTURE PROSPECT: While the post-antimetabolite era of GFS may have presaged a downturn in the use of contemporary GDDs, it also heralds an opportunity to deconstruct some dated design concepts and move forward. For example, the rational basis for using a plate element to physically maintain a drainage reservoir might be questioned if sub-conjunctival fibrosis could be controlled pharmacologically. A large surface area of relatively rigid foreign material may simply exacerbate the inflammatory stimulus to progressive fibrosis. Realizing this, a number of investigators are currently re-exploring anterior GDDs (transscleral implants with no plate element). Clinical results are not available yet, but success will depend on a marriage of design and biomaterials improvements with well controlled pharmacological modulation of wound healing. 15

Recent advances in ocular biomaterials technology over the prospect of implanting biologically inert GDDs with rigidity and biointegration characteristics designed to eliminate micromotion. These new biomaterials may greatly enhance filtration longevity, and if flow resistance and extrinsic leakage can also be controlled, there is no reason in principle why GDDs might not be used in routine GFS. 16

The premise here is that accurate control over flow resistance can be reproduced more easily in an implant than in the tissues themselves. Flow resistance in trabeculectomy depends on suture tension and, where suture lysis/release techniques are used, suture positioning. These factors are subjectively controlled and early postoperative hypotony remains common. ${ }^{16}$ Poor flow control has also been a particular problem for laser sclerostomy techniques. With current laser delivery systems, sclerostomy dimensions vary initially, and are later modified by wound healing to a variable extent. In contrast, sub-micrometre accuracy is possible for key dimensions in implant manufacture, and GFS without hypotony is a realistic aim.

To gain a wider acceptance, development of the next generation of GDDs must be informed by improved flow performance and biocompatibility testing. Inclusion criteria and outcome measures for clinical trials should also be better defined.

The current standing of GDDs is in some ways analogous to that of intraocular lenses in the early 1970s, with frequent complications attributable to design and material inadequacies. Just as improved intraocular lenses have revolutionized cataract surgery in the recent past, new materials and design departures may transform filtration surgery with GDDs in the near future. 


\section{REFERENCES:}

1. Rhee D J. Glaucoma drainage devices. Color Atlas And Synopsis Of Clinical Ophthalmology Wills Eye Institute Glaucoma.2nd ed. Philadelphia; 2012. pp 376-92.

2. Tombran-Tink, Joyce B, Colin JR, Joseph F. Glaucoma drainage devices. Visual Prosthesis and Ophthalmic Devices Ophthalmology Research.1 ${ }^{\text {st }}$ ed.Calgary2007, pp 173-190.

3. Coleman AL. Advances in glaucoma treatment and management. Investigative Ophthalmol \& Visual Science, Special Issue 2012; 53 (5): 2491-4.

4. Rouse JM, Sarkisian SR Jr. Mini-drainage devices: the Ex-PRESS Mini-Glaucoma Device. Dev Ophthalmol 2012; 50: 90-5.

5. Hunter KS, Fjield T, Heitzmann H. Characterization of micro-invasive trabecular bypass stents by ex vivo perfusion and computational flow modelling. Clinical Ophthalmol 2014: 8; 499-506.

6. Bahler CK, Smedley GT, Zhou J, Johnson DH. Trabecular bypass stents decrease intraocular pressure in cultured human anterior segments. Am J Ophthalmol 2004; 138: 988-94.

7. Bettin P, Matteo FD. Glaucoma: Present Challenges and Future Trends. Ophthalmic Res 2013; 50: 197-208.

8. Manal HA, George B, Edward JR. Glaucoma drainage devices: pros and cons. Curr Opinion Ophthalmol 1999; 10 (2): 147-53.

9. Mandal AK. Current concepts in the diagnosis and management of developmental glaucomas. Indian J Ophthalmol 1993; 41: 51-70.

10. Thieme H. Current Status of Epibulbar Anti-glaucoma Drainage Devices in Glaucoma Surgery. Dtsch Arztebl Int 2012; 109 (40): 659-64.

11. Ayyala RS, Harman LE, Norris BM.Comparision of different biomaterials foe GDDs. Arch Ophthalmol 2000; 117: 233-6.

12. Ayyala RS, Harman LE, Norris BM.Comparision of different biomaterials foe GDDs Part 2. Arch Ophthalmol 2000; 118: 1081-4.

13. Singh P, Kuldeep K, Tyagi M, Sharma PD, Kumar Y. Glaucoma drainage devices. J Clin Ophthalmol Res 2013; 1: 77-82.

14. Olmos LC, Lee RK. Medical and Surgical Treatment of Neovascular Glaucoma. Int Ophthalmol Clin. 2011; 51 (3): 27-36.

15. Brandão LM, Grieshaber MC. Update on Minimally Invasive Glaucoma Surgery (MIGS) and New Implants. Journal of Ophthalmolog 2013; 2013: 1-12.

16. I Parul, MR Marlene. Novel Glaucoma Surgical Devices. IN: Shimon R editor. Glaucoma Basic and Clinical Concepts.1 ${ }^{\text {st }}$ ed Croatia: InTech Europe; 2012. pp 417-42.

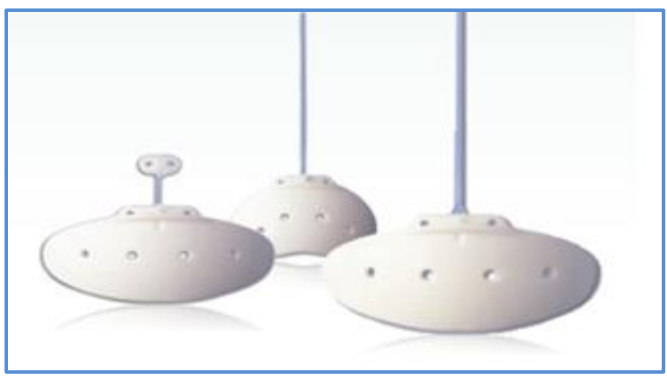

Fig. 1: Baerveldt Shunt 
REVIEW ARTICLE

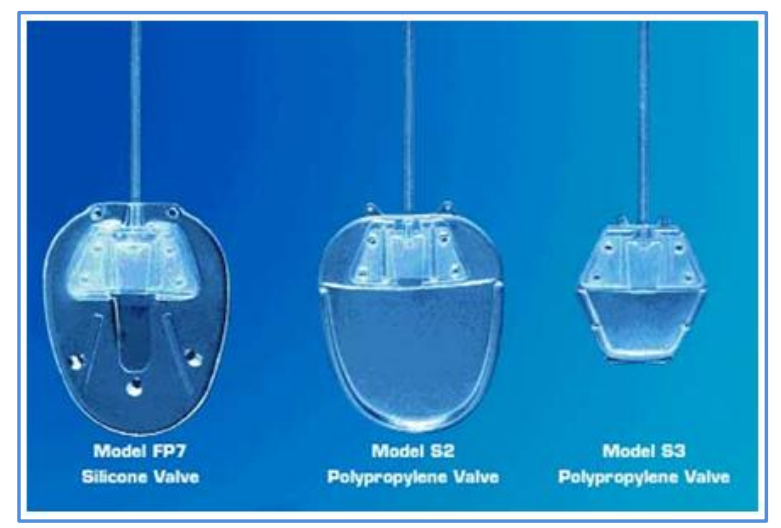

Fig. 2: Ahmed Glaucoma Valve

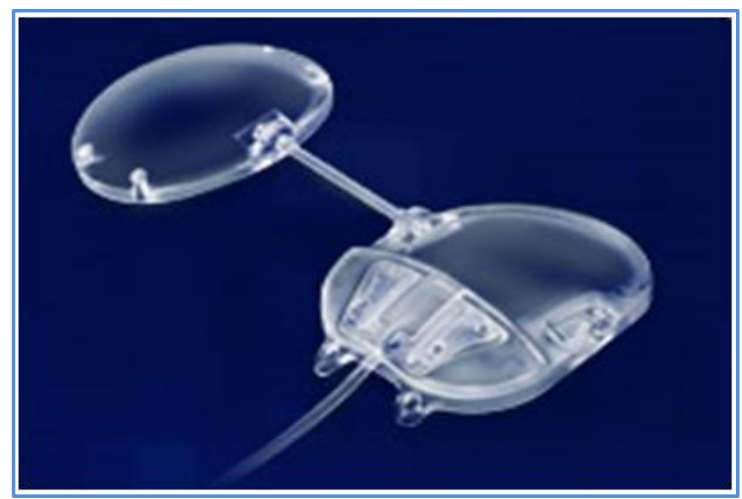

Fig. 3: Ahmed Glaucoma Valve with extra plate

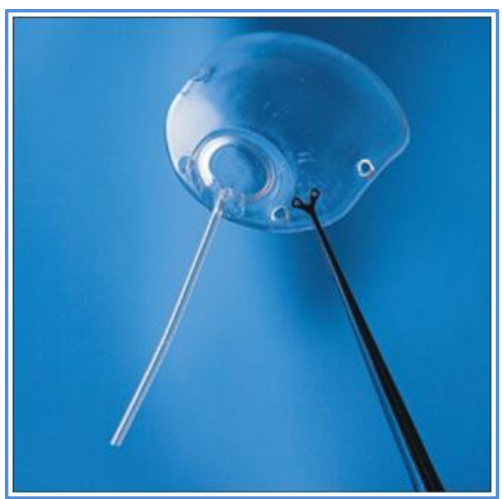

Fig. 4: Molteno Implant 


\section{REVIEW ARTICLE}

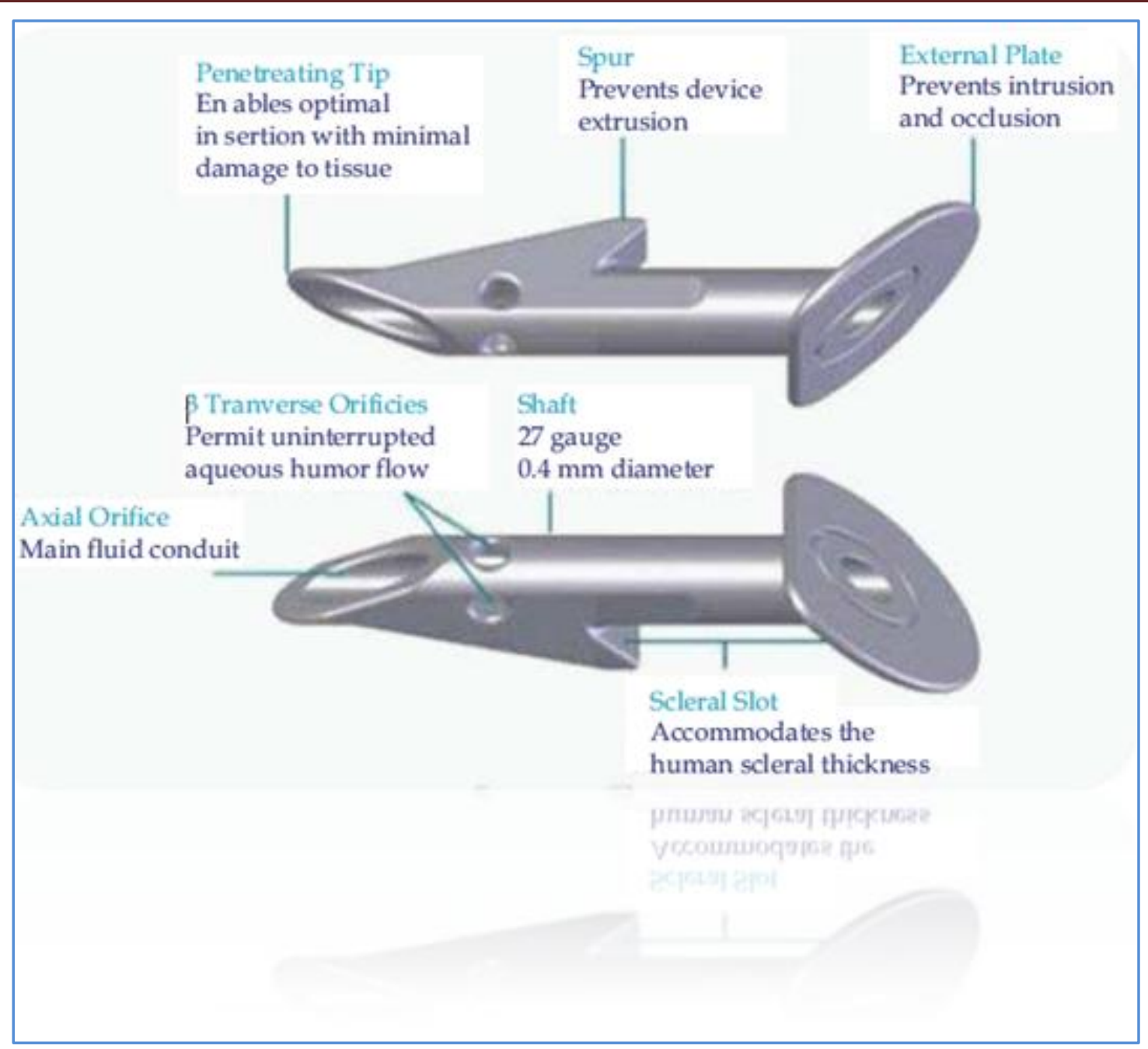

Fig. 5: Ex PRESS miniature glaucoma shunt

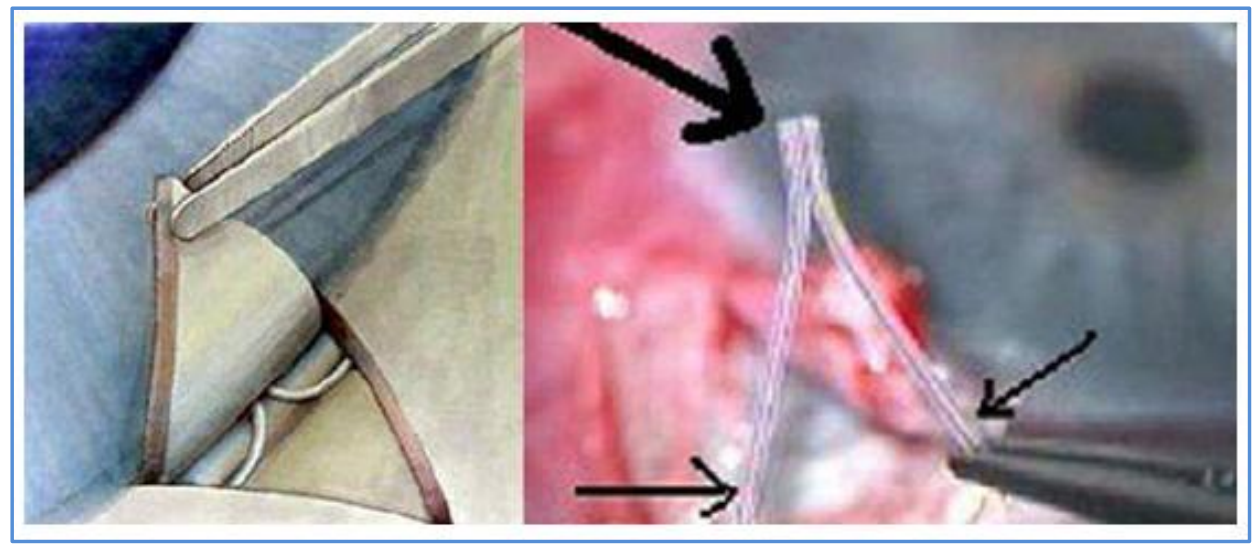

Fig. 6: EYEPASS glaucoma shunt 


\section{REVIEW ARTICLE}

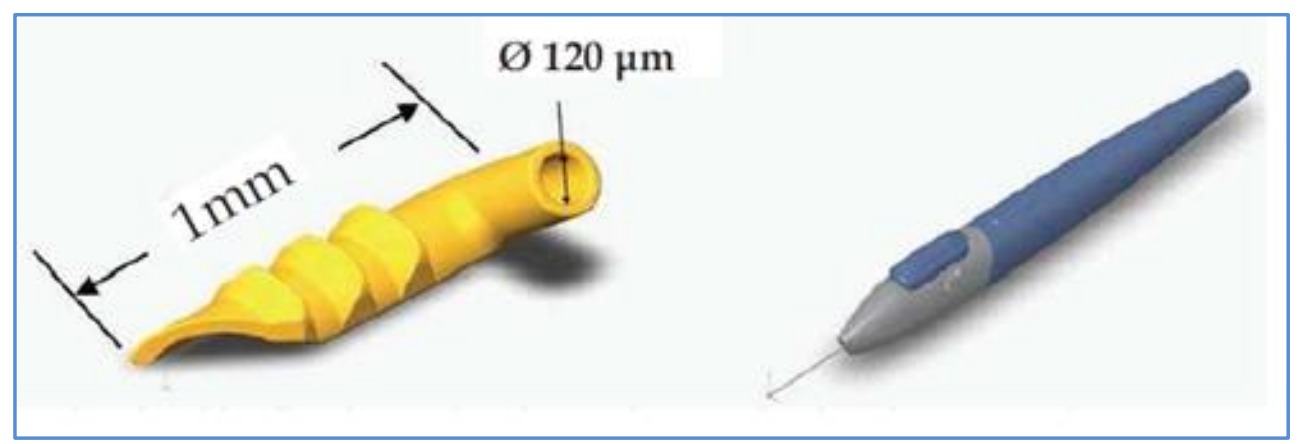

Fig. 7: i-Stent

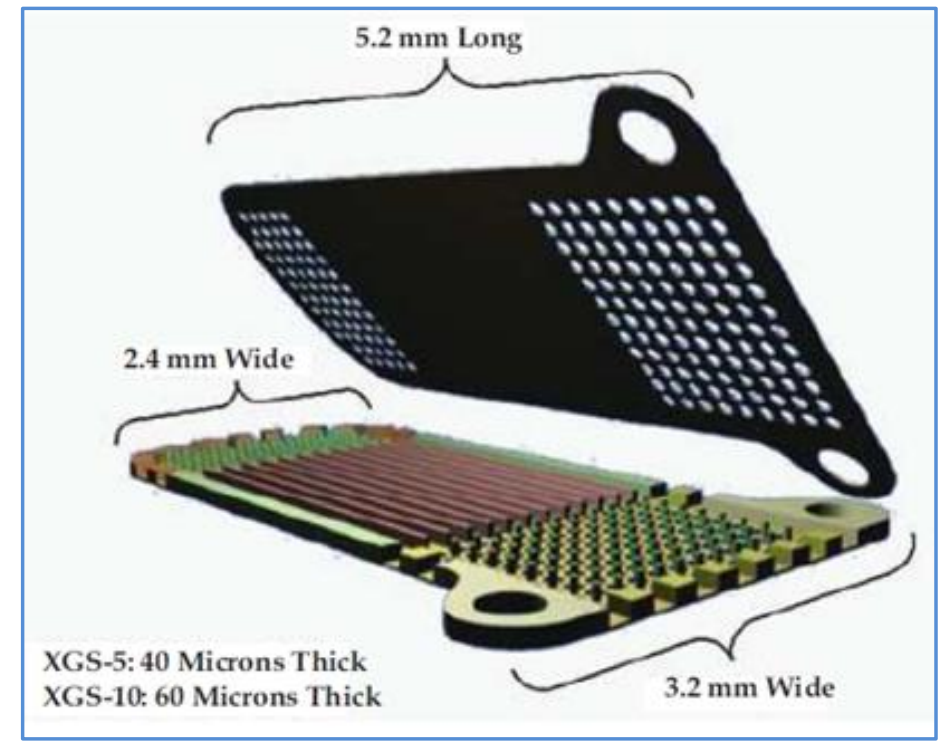

Fig. 8: Deep light Gold shunt 


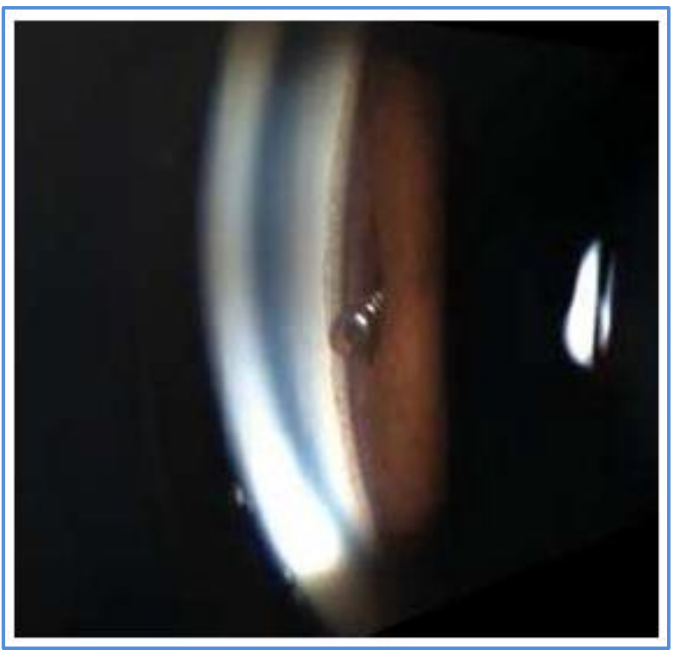

Fig. 9: Transcend Cy Pass glaucoma implant

\section{AUTHORS:}
1. P. Mishra
2. Parth Rana
3. S. Manavalan
4. Neha $\mathrm{H}$.
5. Abbin G. M.
6. V. S. Naggalakshmi
7. Latha Priyangaa
8. R. Vinnarasi

\section{PARTICULARS OF CONTRIBUTORS:}

1. Professor \& HOD, Department of Ophthalmology, RMCCH, Annamalai University, Annamalai Nagar.

2. Post Graduate, Department of Ophthalmology, RMCCH, Annamalai University, Annamalai Nagar.

3. Professor, Department of Ophthalmology, RMCCH, Annamalai University, Annamalai Nagar.

4. Post Graduate, Department of Ophthalmology, Dr. D. Y. Patil Medical College \& University, Pimpri, Pune.
5. Post Graduate, Department of Ophthalmology, RMCCH, Annamalai University, Annamalai Nagar.

6. Post Graduate, Department of Ophthalmology, RMCCH, Annamalai University, Annamalai Nagar.

7. Post Graduate, Department of Ophthalmology, RMCCH, Annamalai University, Annamalai Nagar.

8. Post Graduate, Department of Ophthalmology, RMCCH, Annamalai University, Annamalai Nagar.

\section{NAME ADDRESS EMAIL ID OF THE CORRESPONDING AUTHOR:}

Dr. Parth Rana, \# T4/2 Suham Appartment, Above Pinky's Restaurant, OP Main Road, Annamalai Nagar, Chidambaram, Tamil Nadu-608002.

Email: dr.parth.rana@gmail.com

Date of Submission: 04/11/2014. Date of Peer Review: 05/11/2014. Date of Acceptance: 12/11/2014. Date of Publishing: 17/11/2014. 